\title{
Ensemble Forecasting Methods in DCF Modelling of the Fair Value of Enterprises
}

\author{
Volodymyr A. Viedienieiev \\ Department of Economic and Mathematical Modelling, Kyiv National Economic University named after Vadym Hetman, 03057, \\ Kyiv, Ukraine
}

Received April 16, 2021; Revised June 24, 2021; Accepted July 20, 2021

\begin{abstract}
Cite This Paper in the following Citation Styles
(a): [1] Volodymyr A. Viedienieiev, "Ensemble Forecasting Methods in DCF Modelling of the Fair Value of Enterprises," Universal Journal of Accounting and Finance, Vol. 9, No. 4, pp. 869 - 874, 2021. DOI: 10.13189/ujaf.2021.090432.
\end{abstract}

(b): Volodymyr A. Viedienieiev (2021). Ensemble Forecasting Methods in DCF Modelling of the Fair Value of Enterprises. Universal Journal of Accounting and Finance, 9(4), 869 - 874. DOI: 10.13189/ujaf.2021.090432.

Copyright $\bigcirc 2021$ by authors, all rights reserved. Authors agree that this article remains permanently open access under the terms of the Creative Commons Attribution License 4.0 International License

\begin{abstract}
The purpose of this study is to improve the methodology for assessing the fair value of enterprises based on the DCF model with the use of ensemble methods for predicting the selling price of their products. The study compares the fair values of three Ukrainian agricultural enterprises. The value of each company was calculated in several ways: using forecast data from statistical agencies, calculated forecast values, and real indicators. The methodology is based on the use of methods and models for forecasting time series. The study uses neural networks, as well as prediction methods such as linear regression, FB Prophet model, Holt-Winters exponential smoothing method, SARIMA, XGBoost, which are combined into a single ensemble with the use of the stacking method. The study employed such general scientific methods as analysis, synthesis, abstraction, and comparison. Also, methods of graphical and tabular presentation of materials were applied. Statistical modelling was used to determine the parameters of the model. The study found that the DCF model can potentially be improved by using ensemble methods when predicting metrics such as inflation, exchange rates, and the selling price of goods and services. These metrics have a significant impact on the final result of the model and therefore the slightest changes in these input data can lead to significant deviations in the result. It was demonstrated that the use of ensemble methods only at the selling price can increase the accuracy of the model by $5-15 \%$. It is advisable to use the results of the study in the investment activities of companies, in mergers and acquisitions of companies, as well as in measuring the fair
\end{abstract}

or investment value of companies.

Keywords Value Estimation, Neural Networks, Machine Learning, Efficiency Analysis, Inflation

\section{Introduction}

The activities of any company can be divided into operating, financial and investment. When established, companies often focus on operating and financial activities. As they grow, companies look for opportunities to further develop, increase profits and increase their margins. Thus, the investment activity of companies comes to the fore, because due to investments, companies are able to grow and expand. At the same time, it does not matter whether it will be horizontal, vertical expansion or simply an increase in production capacity. In any case, the company will have to engage in investment activities [1; 2].

Investments are generally thought to be cash, securities, other property, including property rights, other rights that have a monetary value, invested in objects of entrepreneurial and (or) other activities in order to make a profit and (or) achieve other benefits [3]. Thus, the investment object is the key parameter in investments. Companies are the most frequently invested, as the M\&A process provides an opportunity to integrate with the original company and thereby improve operating performance and gain a competitive advantage in the 
marketplace $[4 ; 5]$. Despite the need to acquire companies, the question of the value of companies always arises, since it makes no sense to buy a company for a price that exceeds the value of a similar company on the market. Thus, it is customary to evaluate companies and calculate their fair value. The fair value of a company is an estimate of the value of the company, taking into account all sources of its financing: debt obligations, preferred shares, minority interests and equity shares of the company [6;7].

The most commonly used model for measuring fair value is the discounted cash flow model (DCF model). The essence of this model is that it determines the current asset value, based on forecasts of how much money this asset will bring in the future, which allows calculating future cash flows for the investor [8]. Their use, along with the use of the discount rate, which is often the weighted average cost of capital, allows to find the current value of the asset. Despite the widespread use of DCF models, they have some disadvantages $[9 ; 10]$. Such disadvantages should include the uncertainty of future events, the ability to manipulate the input data of the model to obtain the desired result, as well as ignoring factors such as entrepreneurial decisions, management competence, etc. Of all the above problems, the biggest is the problem of uncertainty of future events, which leads to the fact that with a slight deviation of the future values of indicators from the expected ones, the current value can change significantly and thereby reduce the accuracy and adequacy of the evaluation $[11 ; 12]$.

Modern methods and models make possible to more accurately predict factors that arise in the future. So, with greater accuracy it is possible to determine future exchange rates, inflation and prices of goods and services [13]. Unfortunately, at the moment, most independent evaluators use the simplest forecasting methods, such as linear data extrapolation or expert methods, which raises doubts about the adequacy of the input data for DCF models. Thus, for forecasting prices for raw materials, they often use data from international statistical agencies, which do not take into account local market characteristics $[14 ; 15]$.

In recent decades, neural networks have attracted considerable attention of specialists, which in many cases allow to achieve better results in forecasting time series than traditional prognostic models. At the moment, there are many configurations of neural networks, among which recursive neural networks have recently been very popular, which have proven themselves well when working with time series [16]. Despite the popularity of neural networks, traditional methods are still widespread, since they are less demanding on the computational capabilities of computer hardware, and are also more stable [17].

In order to neutralise the disadvantages of both neural networks and traditional forecasting methods, the author proposes to use ensemble forecasting methods, which consist in the joint use of several models to obtain a better result compared to the results of each model separately $[18 ; 19]$.

DCF simulation results are highly dependent on the input data, as well as on the assumptions about future events that are embedded in the model. Today, the use of modern forecasting methods is still not widely used in DCF forecasting. Instead, the model usually uses inputs from statistical agencies such as the World Bank, IMF, etc. Getting input from statistical agencies requires much less effort than using different prognostic models. However, the use of predictive methods, including neural networks, gives a much more accurate result, which is critical when building a DCF model [20].

One of the questions that needs to be addressed is what kind of input data can be predicted using ensemble forecasting methods, as well as to determine their impact on the final result of the model. In addition, the effectiveness of using ensemble forecasting methods in DCF models in comparison with neural networks and traditional methods for forecasting time series is poorly covered in papers on this subject.

The purpose of the paper is to improve the methodology for assessing the fair value of enterprises based on the DCF model by using ensemble methods for forecasting the selling price of their products.

\section{Literature Review}

There are many approaches to measuring the fair value of enterprises, so it is important to determine which ones have an advantage over others. In the paper [21], the authors considered traditional (the most used model is discrete variable) and modern approaches to assessment and determined that at the moment there is no model that has an advantage over others. Also, the paper clarifies that, ideally, several models should be used to compare the result, as well as the fact that it is necessary to choose models depending on the available data, as well as the current market situation.

When considering the DCF model, it should be borne in mind that it can use different types of cash flows, namely FCFF, FCFE, FCFD. Based on the analysis carried out in [22], it is proved that the fair value obtained using any of the above types of cash flows should be the same, provided that the correct capital structure is applied in the process of calculating the weighted average cost of capital. A separate problem that arises when constructing a DCF model is the evaluator's subjectivity when using the DCF model. So, in [23], the authors prove that "It is very easy to manipulate the DCF analysis to result in the value that you want it to result in by adjusting the inputs. This is even possible without making changes that would be significant from an economist's point of perspective, e.g. a change in the perpetual growth rate or in the WACC by just a few base points. Analysts or business professionals 
have no tools to estimate the input factors with that kind of exactness". It should also be understood that the DCF model is highly dependent on input data. Therefore, the question arises as to how sensitive the model's result is in relation to key parameters of the model, such as inflation rate, capital structure, etc. In paper [24], the author conducted a sensitive analysis of the results of the DCF model to such input data as growth rate and WACC and showed that their changes can lead to a change in the assessment results by $51 \%$. The author pays special attention to the growth rate, since this factor is used when calculating the terminal value, which usually makes up about half of the total company value.

The use of neural networks is described in [25], where the authors use a neural network to predict the future exchange rate, inflation. They use the results from the neural network as input for the DCF model. The paper shows that using neural networks can give better results than using predictions from statistical agencies such as IMF.

The advantages of ensemble forecasting methods are discussed in the paper [26], where the authors consider the use of such ensemble methods as boosting and bagging. The results of their study show that the bagging method is almost always superior to each of the methods used in it. At the same time, boosting can even surpass the results of the bagging method, but at the same time, under certain conditions, it can show no increase in performance or even its deterioration. In [27], the author shows that in most cases the ensemble Stacking method shows better results than each of the models included in it separately.

It should be noted that for the most part, ensemble methods are used to solve data classification problems. Nevertheless, in recent years, more and more ensemble methods are used to solve regression problems, including forecasting by time series. In the paper [28], the authors consider the possibility of using ensemble methods to predict future values of time series. The result of their research shows that ensemble methods show better results than traditional methods such as linear regression, ARMA, ARIMA, SVR. At the same time, ensemble methods also show better results than some neural network configurations. Thus, the authors summarise that it is expedient to use ensemble methods when forecasting time series.

\section{Materials and Methods}

The DCF model helps to measure the value of an investment in an asset based on the cash flow that the asset will generate in the future. It should be understood that the value of the investment is calculated at the current moment, while the cash flow is stretched over time, therefore discounting is used to bring the cash flow to the current period, thus the DCF model used to measure the fair value has 3 components:

1) Modelling cash flow in the forecast period;

2) Calculation of terminal value;

3) Calculation of the discount rate and growth rate;

Cash flow modelling is based on the assumption that the business will operate forever and generate a certain income in the future, which takes into account the level of growth. However, there are exceptions in which the business has a finite lifespan. Basically, such a business is associated with natural resources, for example, mines, wells, etc. In this case, it is necessary to build a cash flow forecast for the entire period of business operation (Eq. 1). For most types of companies, cash flow is modelled for the period required to stabilise it. It is generally accepted that this period is 5 years. In addition, the DCF model calculates the terminal value, which is the value of cash flows in the off-forecast period, taking into account a certain rate of return (Eq. 2). Thus, the calculation of fair value using the DCF model is presented in the equation (Eq. 3).

$$
D C F=\sum_{n=1}^{\infty} \frac{C F_{n}}{(1+i)^{n}}
$$

Where $C F$ - cash flow; $i$ - discount rate; $\mathrm{n}$ - time periods from one to infinity.

$$
T V=\frac{C F *(1+g)}{(i-g)}
$$

Where, $C F$ - stabilised cash flow beyond the forecasting period; $g$ - growth rate; $i$ - discount rate.

$$
\text { Fair Value }=\sum_{n=1}^{t} \frac{C F_{n}}{(1+i)^{n}}+\frac{T V_{t}}{(1+i)^{t}}
$$

Where CF - cash flow; i - discount rate; $\mathrm{n}$ - time periods from one to period $\mathrm{t}$; $\mathrm{TV}$ - terminal value.

There are several methods for determining the discount rate. The most common method is the weighted average cost of capital. This method is used by most companies, as it takes into account both the expected return by investors and the rate of return required to raise funds. The calculation of the weighted average discount rate is presented in the equation (Eq. 4).

$$
W A C C=\frac{D}{D+E} * r_{d} *(1-T)+\frac{E}{D+E} * r_{e}
$$

Where $D=$ market value of debt; $E=$ market value of equity; $\mathrm{r}_{d}=$ cost of debt; $\mathrm{r}_{e}=$ cost of equity; $T=$ corporate tax rate cash flow for each period is calculated as the sum of net income minus gains in working capital and capital expenditures. For calculating the net profit, the main factors are the anticipated income and expenses.

Thus, in the DCF model, the values of 4 main indicators are used as input data, which have a critical impact on the simulation results:

1) discount rate;

2) growth rate;

3) anticipated income;

4) expected losses. 
To predict each of these indicators, it is possible to use neural networks to improve the quality of the model and reduce the impact of unpredictability of future events. In this paper, the author uses neural networks to forecast income.

An ensemble of methods is a meta-algorithm that combines different machine learning techniques into one predictive model in order to reduce variation and improve the quality of forecasting. There are several types of ensembles, of which the most common are bagging, boosting and stacking. Bagging is a meta ensemble machine learning algorithm designed to improve the stability and accuracy of machine learning algorithms used in statistical classification and regression. The algorithm also reduces variance and avoids overfitting. Boosting is an ensemble method that builds an ensemble in sequential increments by training each new model to isolate training instances that previous models misclassified. In some cases, boosting has been proven to give better results than bagging, but tends to overfit with training data. Stacking is a meta algorithm that involves training a training algorithm to combine the predictions of several other training algorithms. First, all other algorithms are trained with valid data, then the combination algorithms are trained to make the final prediction using all the predictions of the other algorithms as an additional input.

In this study, it was stacking that was chosen as the ensemble method, since it consolidates the strengths of each of the subordinate algorithms. In addition, stacking usually provides better performance than any single training model. As mentioned earlier, ensemble methods are meta-algorithms that combine different machine learning models in one way or another. Thus, choosing the right model is of key importance. For research, linear regression created an ensemble of the following methods

1) FBProphet;

2) SARIMA;

3) XGBoost;

4) Holt-Winters model;

5) LSTM implementation of Recursive Neural Network (RNN).

FBProphet - a model that has three main components: seasonality, trends, holidays or events. In this model, time was used for several linear and non-linear functions. It uses linear regression as its base model, but it can also switch to non-linear models.

SARIMA - an extension of ARIMA models. SARIMA takes into account the seasonal effect, which is important when forecasting time series associated with prices for goods and services, as they often have a certain seasonality.

XGBoost - a decision tree based ensemble machine learning algorithm that uses a gradient boosting framework. This algorithm is based on Friedman's paper "Greedy function approximation: a gradient boosting machine" [29] and solves many data science problems in a fast and accurate way, especially when the problem is small/medium sized data in tabular format.

Holt-Winters - a time series forecasting model that integrates three aspects of time series: moving average, trend, and seasonality. It uses exponential smoothing to encode many values from the past and use them to predict "typical" values for the present and future.

Long short-term memory (LSTM) - a modified version of recurrent neural networks (RNN) that is capable of learning long-term dependencies. This type of neural networks was first presented by Sepp Hochreiter and Jürgen Schmidhuber in 1997 [30]. LSTMs are excellent at solving a variety of problems and are now widely used, especially when forecasting time series in which there is a time lag of unknown duration.

\section{Results and Discussion}

To calculate the efficiency of using ensemble forecasting methods in constructing the DCF model, the author first carried out a comparative analysis of the effectiveness of forecasting the future selling price of barley, wheat and corn by different models based on weekly data for 2009-2017.

A comparative analysis of the effectiveness of both each model separately and all models combined into an ensemble was carried out. The root-mean-square error (RMSE) was used as a metric for calculating the effectiveness of the models. Detailed results are presented in the Table 1.

Table 1. RMSE for different prognostic models

\begin{tabular}{|c|c|c|c|}
\hline & Barley & Wheat & Maize \\
\hline Prophet & 6.30 & 7.61 & 11.73 \\
\hline SARIMA & 7.20 & 6.55 & 15.66 \\
\hline XGBoost & 6.11 & 6.77 & 12.99 \\
\hline Holt-Winters model & 8.15 & 8.39 & 13.36 \\
\hline LSTM & 6.22 & 6.71 & 12.81 \\
\hline Ensemble model & 5.48 & 5.44 & 9.57 \\
\hline
\end{tabular}

Analysing the results obtained, it is evident that the ensemble method is the best model for forecasting time series. Comparing the RMSE of the ensemble model with the average RMSE of the other 5 models, it is 19\%-28\% lower. Since the ensemble method showed the best results, the sales price obtained by this method was used in the DCF model.

To determine the efficiency of using the DCF model using ensemble forecasting methods, the author used 3 variants of the input data for the model, namely:

1) a model built using actual data;

2) a model that uses forecasts from statistical agencies;

3) a model built with predictive data obtained as a result of applying the ensemble method. 
Table 2. Projected price of wheat, barley and maize in 2013-2017

\begin{tabular}{|c|c|c|c|c|c|c|}
\hline Data source & Product & 2013 & 2014 & 2015 & 2016 & 2017 \\
\hline \multirow{3}{*}{ Actual data } & Barley & 226 & 164 & 147 & 142 & 161 \\
\cline { 2 - 7 } & Maize & 200 & 176 & 144 & 163 & 162 \\
\cline { 2 - 7 } & Wheat & 232 & 196 & 159 & 164 & 184 \\
\hline \multirow{3}{*}{ World Bank } & Barley & 209 & 196 & 182 & 180 & 179 \\
\cline { 2 - 7 } & Maize & 214 & 199 & 185 & 183 & 182 \\
\cline { 2 - 7 } & Wheat & 247 & 231 & 208 & 208 & 209 \\
\hline \multirow{3}{*}{ Ensemble methods } & Barley & 220 & 172 & 151 & 145 & 156 \\
\cline { 2 - 7 } & Maize & 207 & 179 & 149 & 164 & 170 \\
\cline { 2 - 7 } & Wheat & 238 & 206 & 174 & 168 & 175 \\
\hline
\end{tabular}

In all three models, the only variable whose values differed for different models was the future selling price of the product, while the values of other variables were the same for all three models. These variables were growth rate, debt and equity share, initial operating indicators, etc. It should be noted that changes in the selling price of products in the forecast period also affected the terminal value. For the model built according to the classical scheme, the forecast sales prices from World Bank for January 2013 were used [31]. On their basis, the rates of growth in product prices for 2014-2018 were calculated, which were used in the model. For the model, which was built using actual data, historical data for Ukraine for 2014-2018 provided by APK-Inform [32] was used as the selling price of products. The values of the expected selling prices of the products used in each model are given in the Table 2 .

For comparison, 3 variants of DCF models were built for 3 different companies belonging to the agricultural sector of Ukraine. Fair values were calculated for each variant of the model. Results obtained show that the models built on the basis of ensemble methods give more accurate results than the classic models. The results are shown in the Table 3.

Table 3. Fair value of companies, mln. USD

\begin{tabular}{|c|c|c|c|}
\hline & Company 1 & Company 2 & Company 3 \\
\hline Actual data & 278 & 465 & 339 \\
\hline $\begin{array}{c}\text { Classic } \\
\text { model }\end{array}$ & 211 & 573 & 380 \\
\hline $\begin{array}{c}\text { Ensemble } \\
\text { method }\end{array}$ & 237 & 511 & 362 \\
\hline
\end{tabular}

\section{Conclusions}

Measuring the fair value of companies is one of the important tasks for the financial and investment activities of a company, and is also widely used in mergers and acquisitions. To measure it, most experts use the widely known discounted cash flow (DCF) model. DCF modelling results in forecasted discounted cash flows, which are calculated based on the expected level of future income and expenses. Traditionally, most companies use data from reputable statistical agencies (World Bank, IMF, BMI etc.) as input to their DCF models. However, such data are often quite different from the actual, especially in the context of the projected prices for raw materials/products of enterprises.

In this study, the author conducted a comparative analysis of the use of the ensemble method for forecasting the sales price and the use of projected prices obtained by the classic method (using data from statistical agencies) on the example of three companies in the agricultural sector of Ukraine. Based on the data obtained, DCF models were built and the analysis of the obtained fair values of the companies was carried out.

The results obtained in the paper show that the ensemble model shows better predictive results than each model used in it separately. In addition, the use of projected sales prices obtained using this model can significantly improve the DCF simulation result compared to the classical model.

\section{REFERENCES}

[1] N. Israfilov. I. Ablaev, A. Seisinbinova, T. Sakulyeva. Impact of supply chain management strategies on the performance indicators of small and medium-sized businesses, International Journal of Supply Chain Management, Vol. 9, No. 4, 544-552, 2020.

[2] E. Sidorova, A. Tikhonova. Assessment of the fiscal effect of the tax reform options until 2019: The case of Russia, Economic Annals-XXI, Vol. 164, No. 3-4, 45-48, 2017.

[3] Y. Y. Kostyukhin. Enhancement of labor efficiency in coal mining industry, Gornyi Zhurnal, Vol. 10, 41-44, 2016.

[4] G. V. Kruzhkova, Y. Y. Kostyukhin, I. M. Rozhkov. Choice procedure for expedient composition of electronic waste, Mining Informational and Analytical Bulletin, Vol. 2018, No. 9, 47-57, 2018.

[5] E. Y. Sidorova, L. I. Goncharenko. Tax regulation of 
customs payments in the state policy of Russia, Lecture Notes in Networks and Systems, Vol. 115, 636-642, 2020.

[6] A. S. Basyuk, A. Y. Anisimov, V. V. Prokhorova, O. N. Kolomyts, F. V. Shutilov. Administration management in the innovation cluster, International Review of Management and Marketing, Vol. 6, No. 6, 180-184, 2016.

[7] I. V. Babenko, A. Y. Anisimov, V. Y. Melnikov, I. A. Kubrak, I. I. Golubov, V. L. Boyko. Sustainable supply chain management in city logistics solutions, International Journal of Supply Chain Management, Vol. 9, No. 2, 1081-1085, 2020.

[8] E. I. Bakhtigozina, E. Efremova, E. A. Shevereva, A. A. Kurashova, E. I. Nalbatova. Fraud in the organization and direction of control in order to prevent it, Espacios, Vol. 39, No. 39, 1-6, 2018.

[9] E. I. Efremova, A. A. Kurashova, I. S. Medina, E. A. Fedchenko, M. L. Vasyunina, E. I. Bakhtigozina. Organization and functioning of the internal control service in an outsourcing organization, Astra Salvensis, Vol. 1, 491-497, 2019.

[10] E. A. Lysenko, M. N. Mechikova. The impact of the results of industrial production on the effectiveness of small business development in agriculture, Vestnik Sibirskogo Instituta Biznesa i Informatsionnykh Tekhnologiy, Vol. 3, No. 19, 53-58, 2016.

[11] A. V. Minakov. Assessment of efficiency of investment strategy of insurance company, Ekonomika i Predprinimatelstvo, Vol. 8, No. 49, 522-526, 2014.

[12] A. V. Minakov. The role of foreign investment in the revitalization innovation in the face of uncertainty, Ekonomika i Predprinimatelstvo, Vol. 11-2, No. 40, 47-50, 2013.

[13] T. Sakulyeva. The MAAS system and its problems, E-Management, Vol. 1, No. 2, 30-37, 2018.

[14] A. V. Shelygov, A. S. Filonova, O. E. Gorlova. Basic models of managing organizational changes in modern companies, Ekonomika i Predprinimatelstvo, Vol. 5, No. 106, 1297-1302, 2019.

[15] O. Paliienko, S. Naumenkova, S. Mishchenko. An empirical investigation of the Fama-French five-factor model, Investment Management and Financial Innovations, Vol. 17, No. 1, 143-155, 2020.

[16] S. V. Naumenkova. Financial inclusivity: Economic contents and the approaches to its assessment, Actual Problems of Economics, Vol. 166, No. 4, 363-371, 2015.

[17] R. H. Bekmansurov, K. E. Kovalenko, K. M. Utkina, Y. A. Novikova, E. I. Zatsarinnaya, A. I. Rozentsvaig. State support for persons with disabilities in the field of entrepreneurship, Journal of Entrepreneurship Education, Vol. 22, Special Issue 2, 15-28, 2019.

[18] I. Bashynska, O. Sokhatska, T. Stepanova, M. Malanchuk, S. Rybianets, O. Sobol. Modelling the risks of international trade contracts, International Journal of Innovative
Technology and Exploring Engineering, Vol. 8, No. 11, 2815-2820, 2019.

[19] E. M. Akhmetshin, D. K. Dzhavatov, E. A. Sverdlikova, M. S. Sokolov, O. A. Avdeeva, G. P. Yavkin. The influence of innovation on social and economic development of the Russian Regions, European Research Studies Journal, Vol. 21, Special Issue 2, 767-776, 2018.

[20] I. V. Zhilavskaya, K. K. Onuchina, D. A. Dubover. The design of depressed cities in the Far North and their image in media space after the implosion of the USSR, Visual Anthropology, Vol. 33, No. 2, 164-176, 2020.

[21] A. N. Mohammad. Valuation tools for determining the value of assets: a literature review, International Journal of Academic Research in Accounting, Finance and Management Sciences, Vol. 6, No 4, 63-72, 2016.

[22] P. Adamczyk, A. Zbroszczyk. A key factor of the DCF model coherency, Journal of Economics and Management, Vol. 28, No. 28, 5-22, 2017.

[23] F. Steiger. The Validity of Company Valuation Using Discounted Cash Flow Methods, 2010, Online available fromhttps://arxiv.org/ftp/arxiv/papers/1003/1003.4881.pdf

[24] E. Kramná. Key input factors for discounted cash flow valuations, WSEAS Transactions on Business and Economics, Vol. 11, No. 1, 454-464, 2014.

[25] H. İnce, K. Sayim, S. Z. İmamoğlu, N. Kasap. Investment valuation analysis with artificial neural networks, Dogus University Journal, Vol. 18, No. 2, 85-96, 2017.

[26] D. Opitz, R. Maclin. Popular ensemble methods: an empirical study, Journal of Artificial Intelligence Research, Vol. 11, 169-198, 1999.

[27] D. H. Wolpert. Stacked generalization, Neural Networks, Vol. 5, No. 2, 241-259, 1992

[28] X. Qiu, L. Zhang, Y. Ren, P. N. Suganthan. Ensemble Deep Learning for Regression and Time Series Forecasting, In IEEE SSCI 2014-2014 IEEE Symposium Series on Computational Intelligence, 2014, Online available from https://www.researchgate.net/profile/Le_Zhang25/publicati on/279764894_Ensemble_Deep_Learning_for_Regression _and_Time_Series_Forecasting/links/559a6e0408ae99aa6 2ccb9d7/Ensemble-Deep-Learning-for-Regression-and-Ti me-Series-Forecasting.pdf.

[29] J. H. Friedman. Greedy function approximation: A gradient boosting machine, Annals of Statistics, Vol. 29, No. 5, 1189-1232, 2001.

[30] S. Hochreiter, J. Schmidhuber. Long short-term memory, Neural Computation, Vol. 9, No. 8, 1735-1780, 1997.

[31] The World Bank, Commodity Markets, Online available from https://www.worldbank.org/en/research/commoditymarkets\#3

[32] APK Inform-Agency, Weekly Prices, Online available from https://www.apk-inform.com/ru/prices. 